Results The development of HIE stage 3 was significantly lower in Anapyrexia group (8\%) than in the Normothermia group $(28 \%)$ $(p=0.032 ;[R R]=0.285)$. Fifteen neonates in the anapyrexia group had normal outcome versus only 9 in the normothermia $\operatorname{group}(\mathrm{p}=0.049,[\mathrm{RR}]=0.5)$. The incidence of mortality $(12 \%$ vs $16 \%, p=0.264,[R R]=0.75)$ complications and baseline characteristics were comparable.

Conclusions Anapyrexia if allowed to persist for 72 hours after birth, alleviates the ill effects of hypoxic ischemic insult and results in improved outcome in the neonates particularly the neurodevelopmental outcome at 6 months of age.

\section{PHARMACOKINETICS, CLINICAL EFFICACY AND SAFETY OF LIDOCAINE IN ASPHYXIATED NEWBORNS TREATED WITH THERAPEUTIC HYPOTHERMIA}

doi:10.1136/archdischild-2012-302724.0296

${ }^{1} \mathrm{MPH}$ van den Broek, ${ }^{1}{ }^{2} \mathrm{CMA}$ Rademaker, ${ }^{3} \mathrm{ADR}$ Huitema, ${ }^{4} \mathrm{HLM}$ van Straaten, ${ }^{2} \mathrm{MC}$ Toet, ${ }^{2} \mathrm{LS}$ de Vries, ${ }^{1,5} \mathrm{ACG}$ Egberts, ${ }^{2} \mathrm{~F}$ Groenendaal. ${ }^{~}$ University Medical Centre Utrecht; ${ }^{2}$ Wilhelmina Childrens' Hospital/UMCU, Utrecht; ${ }^{3}$ Slotervaart Hospital/The Netherlands Cancer Institute, Amsterdam; ${ }^{4}$ sala Clinics, Zwolle; ${ }^{5}$ Utrecht Institute for Pharmaceutical Sciences, Utrecht University, Utrecht, The Netherlands

Background and Aims Therapeutic moderate hypothermia for neuroprotection in asphyxiated newborns can influence pharmacokinetics and pharmacodynamics. Lidocaine is administered if seizures persist despite initial therapy. Because cardiotoxicity is a potential risk of lidocaine, dose adjustment under hypothermia might be necessary to prevent toxicity. The aim was to evaluate the effect of hypothermia on lidocaine pharmacokinetics and to evaluate the efficacy and safety under hypothermia.

Methods Hypothermic data were obtained from the SHIVERstudy. Term born newborns with perinatal asphyxia and encephalopathy with lidocaine therapy were included. Therapeutic hypothermia $\left(33.5^{\circ} \mathrm{C}\right.$, for 72 hours) was applied within 6 hours after birth. Lidocaine dosing under hypothermia was reduced; initial dose $2 \mathrm{mg} / \mathrm{kg}$ in 10 minutes, followed by an infusion of $4 \mathrm{mg} / \mathrm{kg} / \mathrm{h}$ during 6 hours. Subsequently the infusion was reduced to $2 \mathrm{mg} / \mathrm{kg} / \mathrm{h}$ during 12 hours, and then stopped.

Data from normothermic newborns were obtained from a previously published study (van den Broek et al., 2011). Pharmacokinetic modelling was performed using NONMEM.

Results 22 hypothermic newborns were included and were compared with 26 normothermic newborns. Based on a onecompartmental model with allometric relationships, lidocaine clearance was decreased by $24 \%$ under hypothermia, while relative metabolite formation was unchanged. During hypothermia no effect of lidocaine on heart frequency could be observed and the observed efficacy, i.e. decrease of seizure activity, was $78 \%$.

Conclusion Hypothermia has a clinically relevant effect on lidocaine clearance. The dosing regimen needs to be adjusted under hypothermia in order to maintain efficacy and to prevent adverse events. This model is currently validated.

\section{DUAL ACTION OF NO SYNTHASES ON BLOOD FLOW AND INFARCT VOLUME CONSECUTIVE TO NEONATAL FOCAL CEREBRAL ISCHEMIA}

doi:10.1136/archdischild-2012-302724.0297

${ }^{1} \mathrm{P}$ Bonnin, ${ }^{2} \mathrm{PL}$ Leger, ${ }^{3} \mathrm{~S}$ Renolleau, ${ }^{2} \mathrm{O}$ Baud, ${ }^{2} \mathrm{C}$ Charriaut-Marlangue. ${ }^{1}$ Physiologie Clinique - Explorations-Fonctionnelles, APHMP; ${ }^{2}$ U676, INSERM Unit 676; ${ }^{3} \mathrm{APHP}$, Service de Réanimation Pédiatrique, Paris, France

Research into neonatal ischemic brain damage is impeded by the lack of a complete understanding of the initial hemodynamic mechanisms resulting in a lesion, particularly that of NO-mediated vascular mech- anisms. In a neonatal stroke rat model, we recently show that collateral recruitment contributes to infarct size variability.

Non-specific and selective NO synthase (NOS) inhibition were evaluated on cerebral blood-flow changes and outcome in a P7 rat model of arterial occlusion (left middle cerebral artery electrocoagulation with 50 min occlusion of both common carotid arteries). Blood-flow changes were measured by using ultrasound imaging with sequential Doppler recordings in both internal carotid arteries and basilar trunk. Cortical perfusion was measured by using laser Doppler flowmetry. We showed that global NOS inhibition significantly reduced collateral support and cortical perfusion (collateral failure), and worsened the ischemic injury in both gender. Conversely, endothelial NOS inhibition increased blood-flows and aggravated volume lesion in males, whereas in females blood-flows did not change and infarct lesion was significantly reduced. These changes were associated with decreased phosphorylation of neuronal NOS at $\mathrm{Ser}^{847}$ in males and increased phosphorylation in females at 24 hours, respectively. Neuronal NOS inhibition also increased blood-flows in males but not in females, and did not significantly change infarct volumes compared to their respective PBS-treated controls.

In conclusion, both nNOS and eNOS appear to play a key role in modulating arterial blood flow during ischemia mainly in male pups with subsequent modifications in infarct lesion.

\section{ANTENATAL TAURINE SUPPLEMENTATION REDUCES CEREBRAL CELL APOPTOSIS IN FETAL RATS WITH INTRAUTERINE GROWTH RESTRICTION}

doi:10.1136/archdischild-2012-302724.0298

1J Liu, 'XF Wang, ${ }^{2} \mathrm{HY}$ Teng, 'N Yang, 'XT Ren. 'Department of Neonatology and NICU, Bayi Children's Hospital Affiliated with General Hospital of Beijing Military Command; 2Department of Pediatrics, The Second Artillery General Hospital, Beijing, China

Intrauterine growth restriction (IUGR) is closely associated with neonatal and prenatal morbidity, mortality and even with adult diseases. Term infants with IUGR have a five- to seven-fold risk of developing cerebral palsy, compared with gestational age-matched infants with normal birth weights. Our previous study showed that antenatal supplementation of taurine can improve brain ultrastructure of fetal rats with IUGR, but the mechanism remains unclear. This paper was to explore the effect of antenatal taurine supplementation on cerebral apoptosis and glial cell line-derived neurotrophic factor (GDNF)-cysteinyl aspartate specific (caspase-3) in fetal rats with IUGR. Fifteen pregnant rats were randomly divided into 3 groups: control group, IUGR and IUGR+antenatal taurine supplements. Taurine was added to the diet of the taurine group at a dose of $300 \mathrm{mg} / \mathrm{kg} \cdot \mathrm{d}$ from 12 days after conception until natural delivery. Two fetal rats were chosen in every litter. brain cellular apoptosis was detected using TUNEL, and the changes in protein expression of GDNF and caspase-3 using immunohistochemistry. The results showed that (1)the counts of apoptotic brain cells in the control group, IUGR group and IUGR with antenatal taurine supplementation group were $(0.28 \pm 0.57) \%$, $(15.30 \pm 5.96) \%$, (9.36 \pm 3.92$) \%$, respectively. (2) The expressions of GDNF in three groups respectively were (93.56 \pm 6.73$),(120.36 \pm 6.23)$ and (139.56 \pm 5.28) $(\mathrm{F}=492.56)$. (3) The expressions of caspase- 3 in three groups respectively were $(7.51 \pm 2.31),(151.33 \pm 24.41)$ and $(37.29 \pm 11.27)$ $(\mathrm{F}=128.18$. Antenatal taurine can significantly decrease brain apoptosis, the mechanism maybe through increasing the expression of GDNF and decreasing the expression of caspase-3. This work was supported by Natural Science Foundation of China (81170577).

\section{PRE-084, A SIGMA-1 RECEPTOR LIGAND, PROTECTS AGAINST EXCITOTOXIC PERINATAL BRAIN INJURY IN NEWBORN MICE}

doi:10.1136/archdischild-2012-302724.0299 